\title{
The impact of selected factors on parameters of weight loss after sleeve gastrectomy
}

\author{
Artur Binda, Paweł Jaworski, Emilia Kudlicka, Adam Ciesielski, Hubert Cabaj, Wiesław Tarnowski \\ Department of General, Oncological and Digestive Tract Surgery, Medical Centre of Postgraduate Education, Orlowski Hospital, \\ Warsaw, Poland
}

Videosurgery Miniinv 2016; 11 (4): 288-294

DOI: https://doi.org/10.5114/wiitm.2016.64999

\begin{abstract}
Introduction: The effectiveness of sleeve gastrectomy has been confirmed in many studies. The impact of individual factors on the parameters of weight loss is still not clear.

Aim: To identify important factors affecting the parameters of weight loss after sleeve gastrectomy.

Material and methods: The impact of prognostic factors and postoperative care components on body mass index (BMI) and percentage excess weight loss (\%EWL) was assessed in a group of 100 consecutive patients who underwent laparoscopic sleeve gastrectomy.

Results: The baseline BMI and body mass in patients with $B M I<30 \mathrm{~kg} / \mathrm{m}^{2}$ and $B M I \geq 30 \mathrm{~kg} / \mathrm{m}^{2} 12$ months after surgery were, respectively, $39.7 \pm 3.2$ vs. $45.9 \pm 4.6 \mathrm{~kg} / \mathrm{m}^{2}, p<0.0001$, and $114.4 \pm 16.8 \mathrm{vs} .130 .3 \pm 18.5 \mathrm{~kg}, p<0.0001 . \mathrm{ln}$ the group with $E W L<50 \%$, the average age was $47.1 \pm 7.7$ vs. $40.6 \pm 10.8$ in the group with $E W L \geq 50 \%, p=0.0025$. In the group of patients with preoperative weight loss, \%EWL was $61.4 \pm 17.2$ vs. $53.3 \pm 19.3 \%$ in the group with no weight loss, $p=0.0496$. Body mass index of the patients who started physical activities was $30.6 \pm 4.2 \mathrm{~kg} / \mathrm{m}^{2} \mathrm{vs}$. $34.0 \pm 5.6 \mathrm{~kg} / \mathrm{m}^{2}$ in the patients with no physical activity, $p=0.0013$, and $\% E W L$ was $63.4 \pm 14.6 \mathrm{vs} .47 .0 \pm 19.9 \%$, $p<0.0001$, respectively. In the case of patients regularly consulted by a dietician BMI was $30.6 \pm 4.2 \mathrm{~kg} / \mathrm{m}^{2} \mathrm{vs} .35 .1$ $\pm 5.5 \mathrm{~kg} / \mathrm{m}^{2}$ in the group without systematic consultations, $p<0.0001$, and $\% E W L$ was $63.1 \pm 15.1 \%$ vs. $42.3 \pm 18.2 \%$, $p<0.0001$.

Conclusions: Lower baseline body weight parameters, younger age, preoperative weight loss, starting systematic physical activities and constant care of a dietician were conducive to achieving better results of surgery, as assessed on the basis of changes in BMI and \%EWL.
\end{abstract}

Key words: sleeve gastrectomy, outcomes, prognostic factors, postoperative care.

\section{Introduction}

Low effectiveness of conservative treatment of obesity, the constantly growing number of obese people and the dissemination of laparoscopic techniques are conducive to the development of bariatric surgery. Surgery is an attractive alternative due to the degree of weight loss, the durability of the effects achieved, the positive impact on the resolution of comorbidities of obesity and reduced cost of longterm care [1-4]. Sleeve gastrectomy is becoming an increasingly popular method among the many methods of surgical treatment of obesity $[5,6]$. The effectiveness and safety of sleeve gastrectomy have been confirmed in many reports [7-9]. Bariatric results of the treatment depend on several factors. The factors whose influence on the outcomes raises doubts include preoperative weight loss, baseline body weight

Address for correspondence

Artur Binda MD, PhD, Department of General, Oncological and Digestive Tract Surgery, Medical Centre of Postgraduate Education, Orlowski Hospital, 231 Czerniakowska St, 00-416 Warsaw, Poland, phone: +48 6013420 16, +48 225841130 , fax: +48 226227833 , e-mail: quiz0@interia.pl 
parameters, age and sex of patients [10-12]. It is also not clear which elements of postoperative care have the greatest impact on the results of sleeve gastrectomy. In the case of conservative treatment, adherence to diet results in a greater weight loss and prevents weight regain in long follow-up periods [13]. Other elements influencing the results of bariatric procedures may include participation in follow-up appointments and starting physical activity in the postoperative period [14-17].

\section{Aim}

The aim of the study was to identify important factors affecting the parameters of weight loss after sleeve gastrectomy.

\section{Material and methods}

The study included the first 100 patients who underwent laparoscopic sleeve gastrectomy in the period from January 2010 to April 2012 (67 women, 33 men). We analyzed prospectively collected data on 93 patients (63 women, 30 men) whose follow-up was at least 12 months. The analysis did not include 5 patients who did not attend the scheduled follow-up visit after 12 months and 2 patients who became pregnant during their follow-up. Patients with body mass index (BMI) of $35-39.9 \mathrm{~kg} / \mathrm{m}^{2}$ and at least one comorbidity, or with $\mathrm{BMI} \geq 40 \mathrm{~kg} / \mathrm{m}^{2}$, were accepted for surgical treatment. Having expressed consent to the surgery, patients were referred for psychological and dietary consultations. During the entire period of treatment the patients were under the care of a dietician. No weight loss or weight gain before the surgery were no grounds to disqualify a patient from the surgery.

The study was approved by the Bioethics Committee at the Medical Centre of Postgraduate Education in accordance with Resolution No. 51/PM/2011 dated 08.03.2011.

\section{Surgical technique and post-operative care}

All patients were treated laparoscopically, with a pneumoperitoneum at a pressure of 12 to $15 \mathrm{~mm} \mathrm{Hg}$ using the Veress needle. The five-trocar technique was used. The width of the sleeve was calibrated using a $36 \mathrm{Fr}$ bougie. The staple line was routinely reinforced with a continuous absorbable suture. Methylene blue was used to carry out the leak test. A Redon drain was placed along the staple line. On the first post-operative day a water-soluble contrast study was routinely performed. In the absence of signs of leakage, drinking was recommended. Patients were discharged on the second day after starting a liquid diet. Follow-up visits were performed after 10 days and 1, 3, 6, 9 and 12 months.

\section{Parameters of weight loss}

The baseline data from the surgery day were used for verifying weight loss. Very good bariatric outcomes were defined as a decrease in BMI below $30 \mathrm{~kg} / \mathrm{m}^{2}$ or achieving excess weight loss (EWL) $\geq 50 \%$.

\section{Identification of prognostic factors and elements of post-operative care influencing parameters of weight loss}

The effect of the following factors was analyzed: age, gender, baseline BMI, baseline body weight, and preoperative weight loss aimed at obtaining a beneficial outcome of the surgery, defined as a decrease in BMI of less than $30 \mathrm{~kg} / \mathrm{m}^{2}$ or $\mathrm{EWL} \geq 50 \%$. The preoperative weight loss was assessed on the basis of the difference between the values recorded on the day of qualification for the surgery and the day of the surgery. The impact of compliance with dietary recommendations, eating sweets, systematic physical activities, dietary care, and follow-up visits on the decrease in BMI and \%EWL was also assessed 12 months after the surgery. Absence during more than one follow-up visit during the follow-up period was determined as a lack of visits. Systematic physical activities were defined as physical activities at least 3 times a week. In the case of including sweets in the diet more than once a week, consumption of them was reported. In the case of finding a lack of compliance with dietary recommendations during more than one follow-up visit, the patient was included in the group not complying with dietary recommendations.

\section{Statistical analysis}

Student's $t$ test was used for comparisons between groups. The analysis was performed using GraphPad Prism v.5.02 for Windows (GraphPad Software, San Diego California USA, www.graphpad. com). A $p$-value of $<0.05$ indicated that the difference was statistically significant. 


\section{Results}

The mean age of the patients was $43.0 \pm 10.2$ years (range: 17-62), the mean weight on the surgery day was $124.9 \pm 19.4 \mathrm{~kg}$ (range: 82.0-180.0), and the mean BMl was $43.7 \pm 5.1 \mathrm{~kg} / \mathrm{m}^{2}$ (range: 34.2-56.0). Differences between men and women in the above parameters are shown in Table I. Four (4.3\%) patients underwent concomitant cholecystectomy for symptomatic cholelithiasis, and $1(1.08 \%)$ patient underwent cruroplasty with interrupted sutures due to a large hiatal hernia. The mean operative time was $123.1 \pm 33.2 \mathrm{~min}$ (range: 60-270). No conversion was recorded. Weight loss parameters are shown in Table II.

\section{Prognostic factors for the outcome} assessed according to the changes in BMI

After 12 months, BMI $<30 \mathrm{~kg} / \mathrm{m}^{2}$ was found in 32 (34.4\%) and $\mathrm{BMI} \geq 30 \mathrm{~kg} / \mathrm{m}^{2}$ in 61 (65.6\%) pa- tients. The mean BMI after surgery in both groups was, respectively, $26.6 \pm 1.9 \mathrm{~kg} / \mathrm{m}^{2}$ (range: $22.1-29.9$ ) and $35.0 \pm 3.8 \mathrm{~kg} / \mathrm{m}^{2}$ (range: $30.0-46.1$ ), $p<0.0001$. A significant influence of the baseline body weight and the baseline BMI on the possibility of BMI decrease below $30 \mathrm{~kg} / \mathrm{m}^{2}$ was observed. Preoperative weight loss was also a factor contributing to the achievement of BMI $<30 \mathrm{~kg} / \mathrm{m}^{2}$, but the difference was not statistically significant. There was no effect of gender or the age of patients on outcome assessed on the basis of changes in BMI. The data are shown in Table III.

\section{Prognostic factors for the outcome assessed on the basis of \%EWL}

Twelve months after the surgery, EWL $<50 \%$ was observed in 35 (37.6\%) patients, and EWL $\geq 50 \%$ in $58(62.4 \%)$ patients. Excess weight loss in both groups was $37.1 \pm 10.4 \%$ (range: $6.8-49.3$ ) and 67.7

Table I. Characteristics of patients

\begin{tabular}{|lccc|}
\hline Parameter & $\begin{array}{c}\text { Female }(N=63) \\
\text { Mean } \pm \text { SD (range) }\end{array}$ & $\begin{array}{c}\text { Male }(N=30) \\
\text { Mean } \pm \text { SD (range) }\end{array}$ & $P$-value \\
\hline BMI $\left[\mathrm{kg} / \mathrm{m}^{2}\right]$ & $43.9 \pm 4.8(34.8-54.9)$ & $43.5 \pm 5.6(43.2-56.0)$ & 0.7395 \\
\hline Body weight $[\mathrm{kg}]$ & $118.8 \pm 15.1(82.0-151.0)$ & $137.6 \pm 21.3(106.0-180.0)$ & $<0.0001$ \\
\hline Age [years] & $42.5 \pm 11.1(17-60)$ & $44.1 \pm 8.0(26-62)$ & 0.4287 \\
\hline
\end{tabular}

Table II. Weight loss parameters

\begin{tabular}{|lcc|}
\hline Evaluated parameter & Before surgery; mean \pm SD (range) & 12 months after surgery; mean \pm SD (range) \\
\hline Body weight $[\mathrm{kg}]$ & $124.9 \pm 19.4(82-180)$ & $91.6 \pm 17.7(56.5-142)$ \\
\hline BMl $\left[\mathrm{kg} / \mathrm{m}^{2}\right]$ & $43.7 \pm 5.1(34.2-56.0)$ & $32.1 \pm 5.1(22.1-46.1)$ \\
\hline Weight loss $(\%)$ & & $26.6 \pm 8.5(3-47)$ \\
\hline Weight loss $[\mathrm{kg}]$ & & $33.3 \pm 11.4(4-64)$ \\
\hline \%EWL & & $56.2 \pm 18.9(6.8-102.1)$ \\
\hline
\end{tabular}

Table III. Prognostic factors for the outcome assessed according to the changes in BMI

\begin{tabular}{|lcccc|}
\hline Patients & Parameter & Mean \pm SD (range) & Mean \pm SD (range) & $P$-value \\
\hline BMI $<30$ as. vs. $B M I \geq 30$ as. & BMl bs. & $39.7 \pm 3.2(34.2-44.6)$ & $45.9 \pm 4.6(36.8-56.0)$ & $<0.0001$ \\
\hline BMI $<30$ as. vs. $\mathrm{BMI} \geq 30$ as. & Age bs. & $42.3 \pm 10.6(17-62)$ & $43.4 \pm 10.0(19-60)$ & 0.6346 \\
\hline BMI $<30$ as. vs. $\mathrm{BMI} \geq 30$ as. & Weight bs. & $114.4 \pm 16.8(82-161)$ & $130.3 \pm 18.5(97-180)$ & $<0.0001$ \\
\hline Pwl. (+) vs. pwl. $(-)$ & BMl as. & $30.7 \pm 4.8(23.4-41.3)$ & $32.8 \pm 5.2(22.1-46.1)$ & 0.0560 \\
\hline Female vs. male & BMl as. & $32.1 \pm 4.6(22.1-43.6)$ & $32.2 \pm 6.1(23.4-46.1)$ & 0.9308 \\
\hline
\end{tabular}

bs. - before surgery, as. - after surgery, pwl. - preoperative weight loss. 
$\pm 12.5 \%$ (range: $50.4-102.1$ ), $p<0.0001$. Excess weight loss was significantly higher in patients with preoperative weight loss, as compared with those without weight loss. The average age in the group of patients with EWL $\geq 50 \%$ was lower than in the group of patients whose EWL was less than $50 \%$. The results are shown in Table IV.

Impact of selected elements

of post-operative care on the parameters of weight loss

Lower BMI was observed in patients adhering to dietary recommendations, regularly attending dietary consultations and in patients who started regular physical activities. Consuming sweets and participation in follow-up appointments had no sig- nificant impact on this parameter. The results are presented in Table V. All of the analyzed elements have a significant impact on the \%EWL. This was particularly evident in the case of performing systematic physical activity and participation in dietary consultations. The data are presented in Table VI.

\section{Discussion}

In recent years, sleeve gastrectomy has become the second most common bariatric procedure performed worldwide [18]. Despite the similarity of the surgical technique, results, in terms of weight loss, achieved in individual patients may vary significantly. In the present study, the degree of weight loss was evaluated on the basis of \%EWL and BMI changes in accordance with the recommendations of 2005

Table IV. Prognostic factors for the outcome assessed on the basis of \%EWL

\begin{tabular}{|lcccc|}
\hline Patients & Parameter & Mean \pm SD (range) & Mean \pm SD (range) & $P$-value \\
\hline EWL $<50 \%$ vs. EWL $\geq 50 \%$ & BMl bs. & $44.9 \pm 5.2(34.2-56.0)$ & $43.0 \pm 4.9(34.8-55.0)$ & 0.0818 \\
\hline EWL $<50 \%$ vs. EWL $\geq 50 \%$ & Age bs. & $47.1 \pm 7.7(24-59)$ & $40.6 \pm 10.8(17-62)$ & 0.0025 \\
\hline EWL $<50 \%$ vs. EWL $\geq 50 \%$ & Weight bs. & $129.9 \pm 22.1(97-180)$ & $121.8 \pm 17(82-161)$ & 0.0528 \\
\hline PWl. (+) vs. pwl. (-) & $\% E W L$ & $61.4 \pm 17.2(29-93)$ & $53.3 \pm 19.3(6.8-102.1)$ & 0.0496 \\
\hline Females vs. males & \%EWL & $56.3 \pm 18.3(6.8-102.1)$ & $55.4 \pm 20.4(13.9-93.4)$ & 0.8335 \\
\hline
\end{tabular}

bs. - before surgery, as. - after surgery, pwl. - preoperative weight loss.

Table V. Impact of selected elements of post-operative care on BMI 12 months after surgery

\begin{tabular}{|lccc|}
\hline Evaluated factors & BMI, mean \pm SD (range) & BMI, mean \pm SD (range) & $P$-value \\
\hline Diet $(+)$ vs. diet $(-)$ & $31.5 \pm 4.8(22.1-41.4)$ & $33.9 \pm 5.7(25.7-46.6)$ & 0.0481 \\
\hline Sweets $(-)$ vs. sweets $(+)$ & $31.7 \pm 5.1(22.1-1.4)$ & $32.5 \pm 5.1(25.8-46.1)$ & 0.4806 \\
\hline Pa (+) vs. pa (-) & $30.6 \pm 4.2(23.4-39.9)$ & $34.0 \pm 5.6(22.1-46.1)$ & 0.0013 \\
\hline Dc (+) vs. dc. (-) & $30.6 \pm 4.2(22.1-41.4)$ & $35.1 \pm 5.5(25.7-46.1)$ & $<0.0001$ \\
\hline Fv. $(+)$ vs. fv (-) & $31.6 \pm 5.1(22.1-46.4)$ & $33.7 \pm 4.8(25.7-43.6)$ & 0.0750 \\
\hline
\end{tabular}

Pa. - physical activity, dc. - dietary consultations, fv. - follow-up visits.

Table VI. Impact of selected elements of post-operative care on \%EWL 12 months after surgery

\begin{tabular}{|lccc|}
\hline Evaluated factors & \%EWL, mean \pm SD (range) & \%EWL, mean \pm SD (range) & $P$-value \\
\hline Diet (+) vs. diet (-) & $59.7 \pm 17.5(22.5-102.1)$ & $45.4 \pm 19.4(6.8-76.6)$ & 0.0014 \\
\hline Sweets (-) vs. sweets (+) & $60.1 \pm 18.2(22.5-102.1)$ & $51.6 \pm 18.9(6.8-81.3)$ & 0.0293 \\
\hline Pa (+) vs. pa (-) & $63.4 \pm 14.6(33.7-93.4)$ & $47.0 \pm 19.9(6.8-102.1)$ & $<0.0001$ \\
\hline Dc (+) vs. dc. (-) & $63.1 \pm 15.1(28.1-102.1)$ & $42.3 \pm 18.2(6.8-81.3)$ & $<0.0001$ \\
\hline Fv. $(+)$ vs. fv(-) & $58.9 \pm 18.5(22.5-102.1)$ & $47.8 \pm 17.9(6.8-76.6)$ & 0.0130 \\
\hline
\end{tabular}

Pa. - physical activity, dc. - dietary consultations, fv. - follow-up visits. 
[19]. In the analyzed group, the above parameters were similar to the data presented in the literature [7, 20-22]. The impact of each factor on the final outcome of the bariatric treatment is still not clear. An additional difficulty in the interpretation of the results is the lack of a clear definition of success of the surgical treatment of obesity. What is more, there are many different definitions and scales [23-26]. The manner of defining success affects the reported results of treatment. In the current study, a very good outcome included $\mathrm{EWL} \geq 50 \%$ and $\mathrm{BMI}$ decrease below $30 \mathrm{~kg} / \mathrm{m}^{2}$. A more restrictive criterion in this approach is to obtain a BMI $<30 \mathrm{~kg} / \mathrm{m}^{2}$.

We did not find any effect of the age or gender of patients on the degree of BMI decrease. In the case of patients with preoperative weight loss, the mean BMI after the surgery was lower than in patients without weight loss, but the difference was not significant. Significant differences were however observed in the case of the baseline weight and BMI. In the group of patients with $\mathrm{BMI}<30 \mathrm{~kg} / \mathrm{m}^{2}$, both the mean weight and BMI before the surgery were lower than in the case of patients with BMI $\geq 30 \mathrm{~kg} / \mathrm{m}^{2}, p<0.0001$. Reports on the impact of initial body weight parameters on \%EWL and the rate of $\mathrm{BMI}$ decrease in the postoperative period are contradictory $[11,27]$. Certainly, it is much more difficult for patients with the initial BMI $>50 \mathrm{~kg} / \mathrm{m}^{2}$ to achieve a decrease of BMI below $30 \mathrm{~kg} / \mathrm{m}^{2}$ [11]. This study confirms the beneficial effect of lower baseline body weight parameters on the possibility of achieving a lower BMI after the surgery. Taking the decrease in BMI below the target as the measure of success, patients with lower body weight parameters should therefore be eligible for surgery. In the current study, a lower baseline BMI also favored higher \%EWL, but the difference was not significant. Other reports also do not confirm any significant influence of the baseline BMI on \%EWL $[11,27]$. Chopra et al. noted higher \%EWL in the group of patients with the baseline $\mathrm{BMI}<50 \mathrm{~kg} / \mathrm{m}^{2}$ as compared to patients $>50 \mathrm{~kg} / \mathrm{m}^{2}$, but the difference was significant only after 6 and 12 months, and it faded after 24 months [12]. Alvarado et al. reported that baseline BMI higher by one was related to achieving EWL lower by $1.34 \%$, but these results concerned the Roux-en-Y gastric bypass [28]. In the present study, a significant impact on the $\% E W L$ was only found in the case of the age of the operated patients and their weight loss before the surgery. Numerous studies have confirmed a beneficial effect of younger age on both the \%EWL and percentage excess body mass index loss (\%EBMIL). Contreras et al. reported EBMIL in patients under 45 years of age, 12 months after the surgery, at the level of $91 \pm 26.6 \%$ and $73.1 \pm 24.1 \%, p<0.0001$, in the group $\geq 45$ years of age. A significant difference was also found when comparing the two groups in terms of the proportion of patients who achieved $E B M I L \geq 50 \%$. In the case of younger patients, the percentage was $97.4 \%$, and it was $85.1 \%$ in the case of older patients, $p<0.001$ [10]. Chopra et al. found that EWL\% was higher in patients $<40$ years of age than in the group $>40$ years of age, but the differences were only significant after 12 and 24 months. After 24 months, the difference between the mean $\%$ EWL in both groups was $11 \%$ [12]. Other reports did not confirm the beneficial effect of patients' younger age on \%EWL [11]. Another factor whose influence is controversial is the preoperative body weight loss. Recommending weight loss before the surgery is not always accepted by patients. Making the surgery conditional on weight loss can promote disqualification of patients for whom bariatric treatment brings measurable health benefits. On the other hand, preoperative body weight loss is an effective way to assess patients' involvement in the therapeutic process [29]. Many studies have shown beneficial effects of preoperative weight loss on the parameters of weight loss in the postoperative period [28-30]. This phenomenon can be maintained only for short periods of follow-up [31, 32]. Not all reports confirm the positive effect of preoperative weight loss [33]. In our study \%EWL in the patients with preoperative weight loss was $61.4 \pm 17.2 \%$, and it was $53.3 \pm 19.3 \%$ in the group of patients with no preoperative body weight loss, $p=0.0496$. The prerequisite to demonstrate a significant effect can be weight loss by a specified value, e.g. excess body weight loss by $5 \%$ [30]. Undoubtedly, in patients with a high initial BMI, weight loss may be justified due to the beneficial effects on the overall health and the reduced risk of perioperative complications.

Many patients' hope for weight loss is associated with the surgery, mostly with no emphasis on lifestyle changes before and after the surgery. Regardless of the type of intervention, failure to comply with recommendations will again result in increased body weight [34]. In order to obtain good treatment results, a comprehensive multidisciplinary team ap- 
proach is needed along with good identification of adverse factors which may occur in the postoperative period. This study confirms a significant impact of compliance with dietary recommendations on decreases in BMI. Avoiding consumption of sweets was less important in this context. The impact of compliance with dietary recommendations is clear in the case of \%EWL. The beneficial effect of constant dietary care is obvious in the case of Roux-en-Y gastric bypass [35]. The present study confirms a clear effect of systematic participation in dietary consultations on decreases in BMI and \%EWL after sleeve gastrectomy. It is important to educate patients on the proper reporting of food intake. This is conducive to identifying the causes of too low weight loss. Attempts to determine the causes of poor weight loss should not cause patients' discomfort and cannot be perceived as negative assessments. In this area of contact with patients, dieticians who have experience in working with bariatric patients should play major roles. The frequency of follow-up visits after the bariatric surgery performed depends on the type of bariatric procedure and comorbidities [14]. Odom et al. reported that the risk of further weight gain in patients after Roux-en-Y gastric bypass is inversely proportional to the frequency of appointments [15]. Regular appointments allow for the identification of patients with possible complications and affect the results of weight loss. In the present study, the patients who systematically attended follow-up visits had significantly higher \%EWL. In the case of their BMI, a tendency to obtain better results was observed. Unfortunately, in most cases, the willingness of patients to participate in follow-up appointments after bariatric surgery is much lower than before the surgery [36, 37]. Intensive care in the postoperative period and the patients' constant contact with the team providing treatment are essential, particularly in later years after the surgery [38, 39]. Data on the impact of follow-up visits on the outcomes of sleeve gastrectomy are limited. This study showed that it is a factor favorably affecting the degree of weight loss. The importance of physical activities in the treatment of obesity was highlighted in the recommendations of 1998. Physical activities should be part of a comprehensive treatment program for obesity and a factor preventing re-gaining body weight [40]. The beneficial effect of physical activities on $\% E W L$ and BMI decrease was also confirmed in the present study. Patients should be advised to take up moderate aerobic exercises first for a minimum of 150 min and, eventually, 300 min per week, including strength training 2-3 times a week [14]. Regular physical activities are associated with obtaining better results of weight loss after bariatric surgery [17, 41]. Beneficial effects are particularly evident in the case of increasing the time devoted to physical activities after the surgery, as compared to the period before the surgery [42].

\section{Conclusions}

It can be stated that the younger age of patients and preoperative weight loss are conducive to achieving a higher \%EWL. Lower baseline parameters of weight facilitate very good results, defined as a BMI decrease $<30 \mathrm{~kg} / \mathrm{m}^{2}$. Starting systematic physical exercises, dietetic care and adherence to recommendations in the postoperative period positively influence the parameters of weight loss after sleeve gastrectomy.

\section{Conflict of interest}

The authors declare no conflicts of interest.

\section{References}

1. Sampalis JS, Liberman M, Auger S, et al. The impact of weight reduction surgery on health-care costs in morbidly obese patients. Obes Surg 2004; 14: 939-47.

2. Buchwald $H$, Avidor $Y$, Braunwald $E$, et al. Bariatric surgery: a systematic review and meta-analysis. JAMA 2004; 292: 172437. Erratum in: JAMA 2005; 293: 1728.

3. Clinical Issues Committee of American Society for Metabolic and Bariatric Surgery. Sleeve gastrectomy as a bariatric procedure. Surg Obes Relat Dis 2007; 3: 573-6.

4. Dixon JB, Zimmet P, Alberti KG, et al. International Diabetes Federation Taskforce on Epidemiology and Prevention. Bariatric surgery for diabetes: the International Diabetes Federation takes a position. J Diabetes 2011; 3: 261-4.

5. Buchwald H, Oien DM. Metabolic/Bariatric Surgery Worldwide 2011. Obes Surg 2013; 23: 427-36.

6. Janik MR, Stanowski E, Paśnik K. Present status of bariatric surgery in Poland. Videosurgery Miniinv 2016; 11: 22-5.

7. Bellanger DE, Greenway FL. Laparoscopic sleeve gastrectomy, 529 cases without a leak: short-term results and technical considerations. Obes Surg 2011; 21: 146-50.

8. Bobowicz M, Lehmann A, Orlowski M, et al. Preliminary outcomes 1 year after laparoscopic sleeve gastrectomy based on Bariatric Analysis and Reporting Outcome System (BAROS). Obes Surg 2011; 21: 1843-8.

9. Gagner M, Deitel M, Erickson AL, et al. Survey on laparoscopic sleeve gastrectomy (LSG) at the Fourth International Consensus Summit on Sleeve Gastrectomy. Obes Surg 2013; 23: 2013-7. 
10. Contreras JE, Santander C, Court I, et al. Correlation between age and weight loss after bariatric surgery. Obes Surg 2013; 23: 1286-9.

11. Eisenberg D, Bellatorre A, Bellatorre N. Sleeve gastrectomy as a stand-alone bariatric operation for severe, morbid, and super obesity. JSLS 2013; 17: 63-7.

12. Chopra A, Chao E, Etkin Y, et al. Laparoscopic sleeve gastrectomy for obesity: can it be considered a definitive procedure? Surg Endosc 2012; 26: 831-7.

13. Del Corral P, Bryan DR, Garvey WT, et al. Dietary adherence during weight loss predicts weight regain. Obesity 2011; 19: 1177-81.

14. Mechanick JI, Youdim A, Jones DB, et al. Clinical practice guidelines for the perioperative nutritional, metabolic, and nonsurgical support of the bariatric surgery patient - 2013 update: cosponsored by American Association of Clinical Endocrinologists, The Obesity Society, and American Society for Metabolic Bariatric Surgery. Obesity 2013; Suppl. 1: S1-27.

15. Odom J, Zalesin KC, Washington TL, et al. Behavioral predictors of weight regain after bariatric surgery. Obes Surg 2010; 20: 349-56.

16. Livhits M, Mercado C, Yermilov I, et al. Exercise following bariatric surgery: systematic review. Obes Surg 2010; 20: 657-65.

17. Egberts K, Brown WA, Brennan L, et al. Does exercise improve weight loss after bariatric surgery? A systematic review. Obes Surg 2012; 22: 335-41.

18. Angrisani L, Santonicola A, lovino P, et al. Bariatric Surgery Worldwide 2013. Obes Surg 2015; 25: 1822-32.

19. Oria HE, Carrasquilla C, Cunningham P, et al. Guidelines for weight calculations and follow-up in bariatric surgery. American Society for Bariatric Surgery Standards Committee, 2004 2005. Surg Obes Relat Dis 2005; 1: 67-8.

20. Brethauer SA, Hammel JP, Schauer PR. Systematic review of sleeve gastrectomy as staging and primary bariatric procedure. Surg Obes Relat Dis 2009; 5: 469-75.

21. Abd Ellatif ME, Abdallah E, Askar W, et al. Long term predictors of success after laparoscopic sleeve gastrectomy. Int I Surg 2014; 12: 504-8.

22. Basso N, Casella G, Rizzello M, et al. Laparoscopic sleeve gastrectomy as first stage or definitive intent in 300 consecutive cases. Surg Endosc 2011; 25: 444-9.

23. Michalik M, Bobowicz M, Buchwald $\mathrm{H}$. A numerical scale to assess the outcomes of metabolic/bariatric surgery (NOMS). Videosurgery Miniinv 2015; 10: 359-62.

24. Brolin RE, Kenler HA, Gorman RC, et al. The dilemma of outcome assessment after operations for morbid obesity. Surgery 1989; 105: 337-46.

25. van de Laar AW, Acherman YI. Weight loss percentile charts of large representative series: a benchmark defining sufficient weight loss challenging current criteria for success of bariatric surgery. Obes Surg 2014; 24: 727-34.

26. Menenakos E, Stamou KM, Albanopoulos K, et al. Laparoscopic sleeve gastrectomy performed with intent to treat morbid obesity: a prospective single-center study of 261 patients with a median follow-up of 1 year. Obes Surg 2010; 20: 276-82.

27. Uffort E, Nease B, Canterbury T. Laparoscopic sleeve gastrectomy with comparable weight loss in all obese groups: a VA hospital experience. Am Surg 2013; 79: 739-42.
28. Alvarado R, Alami RS, Hsu G, et al. The impact of preoperative weight loss in patients undergoing laparoscopic Roux-en-Y gastric bypass. Obes Surg 2005; 15: 1282-6.

29. Livhits M, Mercado C, Yermilov I, et al. Does weight loss immediately before bariatric surgery improve outcomes: a systematic review. Surg Obes Relat Dis 2009; 5: 713-21.

30. Solomon H, Liu GY, Alami R, et al. Benefits to patients choosing preoperative weight loss in gastric bypass surgery: new results of a randomized trial. J Am Coll Surg 2009; 208: 241-5.

31. Alami RS, Morton JM, Schuster R, et al. Is there a benefit to preoperative weight loss in gastric bypass patients? A prospective randomized trial. Surg Obes Relat Dis 2007; 3: 141-5; discussion 145-6.

32. Becouarn G, Topart P, Ritz P. Weight loss prior to bariatric surgery is not a pre-requisite of excess weight loss outcomes in obese patients. Obes Surg 2010; 20: 574-7.

33. Cassie S, Menezes C, Birch DW, et al. Effect of preoperative weight loss in bariatric surgical patients: a systematic review. Surg Obes Relat Dis 2011; 7: 760-7; discussion 767.

34. Bond DS, Phelan S, Leahey TM, et al. Weight-loss maintenance in successful weight losers: surgical vs non-surgical methods. Int J Obes 2009; 33: 173-80.

35. Faria SL, de Oliveira Kelly E, Lins RD, et al. Nutritional management of weight regain after bariatric surgery. Obes Surg 2010; 20: 135-9.

36. El Chaar M, McDeavitt K, Richardson S, et al. Does patient compliance with preoperative bariatric office visits affect postoperative excess weight loss? Surg Obes Relat Dis 2011; 7: 743-8.

37. Magro DO, Geloneze B, Delfini R, et al. Long-term weight regain after gastric bypass: a 5 -year prospective study. Obes Surg 2008; 18: 648-51.

38. Fried M, Hainer V, Basdevant A, et al. Inter-disciplinary European guidelines on surgery of severe obesity. Int J Obes 2007; 31: 569-77.

39. Shen R, Dugay G, Rajaram K, et al. Impact of patient follow-up on weight loss after bariatric surgery. Obes Surg 2004; 14: 514-9.

40. Clinical guidelines on the identification, evaluation, and treatment of overweight and obesity in adults: executive summary. Expert Panel on the Identification, Evaluation, and Treatment of Overweight in Adults. Am J Clin Nutr 1998; 68: 899-917.

41. Jacobi D, Ciangura C, Couet C, et al. Physical activity and weight loss following bariatric surgery. Obes Rev 2011; 12: 366-77.

42. Bond DS, Phelan S, Wolfe LG, et al. Becoming physically active after bariatric surgery is associated with improved weight loss and health-related quality of life. Obesity 2009; 17: 78-83.

Received: 20.11.2016, accepted: 11.12.2016. 